\title{
Mechanical Characteristics of Ballast Bed under Dynamic Stabilization Operation Based on Discrete Element and Experimental Approaches
}

\author{
Lihua Wang $\mathbb{D}^{D}$, Zemin Zhao $\mathbb{i}$, Jiongli Wang, Xianzeng Li, Yayu Huang, and Tingqiang Yao \\ Faculty of Mechanical and Electrical Engineering, Kunming University of Science and Technology, Kunming, China \\ Correspondence should be addressed to Lihua Wang; kmwanglihua@163.com
}

Received 14 November 2020; Revised 6 February 2021; Accepted 5 March 2021; Published 17 March 2021

Academic Editor: Marcello Vanali

Copyright (C) 2021 Lihua Wang et al. This is an open access article distributed under the Creative Commons Attribution License, which permits unrestricted use, distribution, and reproduction in any medium, provided the original work is properly cited.

\begin{abstract}
To study the mechanical characteristics of ballasted bed under dynamic stability, a three-dimensional discrete element model of ballasted bed with $1000 \mathrm{~mm} \times 700 \mathrm{~mm} \times 550 \mathrm{~mm}$ is established based on the discrete element method. Meanwhile, a simulation test bench with the same size is built for simulation analysis and experimental research. The variation law and trend of settlement, lateral resistance, and compactness of ballasted bed under different excitation frequencies are analyzed comprehensively. The results show that when the excitation frequency is constant, the lateral resistance of sleeper, the settlement of sleeper, and the compactness of track bed under sleeper increase first and then tend to be stable. With the increase in horizontal excitation frequency, lateral resistance of ballast bed, sleeper settlement, and compactness first increase and then decrease after stable operation. The values of these parameters are maximized when the excitation frequency is $36 \mathrm{~Hz}$ which is the relative optimal horizontal excitation frequency of this model.
\end{abstract}

\section{Introduction}

With the development of railway transportation to high speed, heavy load, and large volume, the safety of railway is becoming more and more important. Ballasted track is widely used because of its obvious advantages such as easy maintenance, good shock absorption effect, and easy drainage. For newly built and large maintained railway lines, the ballast bed is loose, the lateral resistance is weak, and the stability of train operation is poor. Through the dynamic stabilization operation of the dynamic track stabilizer, the lateral resistance of the ballast to the sleeper and the overall stability of the train running can be improved fundamentally, to ensure the safety of high-speed train running and shorten or cancel the slow running time of the train [1]. This is of great significance to the present railway transport.

Scholars have done a lot of research on ballasted bed. Fattah et al. [2-5] studied the influence of clay cushion and Geogrid on ballast bed. The results show that with the increase in simulated train load amplitude, the settlement also increases, and the increase in settlement depends on the existence of Geogrid and other parameters studied; with the increase in track speed, the improvement of soft clay model settlement will also increase. Gao et al. [6] established a three-dimensional model of ballasted bed-sleeper for highspeed railway using the discrete element method and studied the influence of cross section size of ballasted bed on lateral resistance and the changing rule of lateral resistance. Liu et al. [7] carried out the longitudinal resistance characteristics of ballast bed under cyclic longitudinal loads with different loading rates and displacement extremes based on the full-scale test model of ballast track structure and discussed the deformation characteristics and resistance characteristics of granular ballast bed under cyclic loading. Wang [8] established a real proportional ballast bed test device and corresponding hydraulic loading system to study the vibration acceleration and settlement of the ballast bed and contact force between sleeper and the bottom of ballast bed under cyclic load with different train speed and axle load and proposed a life prediction and evaluation model of 
ballast bed. Guo et al. [9] conducted the direct shear test on rubber protected ballast (RPB), which showed that RPB had the advantage of increasing the stress distribution of ballast particles, and smaller rubber powder particle size was more suitable to replace ballast particles. Zhao et al. [10] simulated the ballast particle model by using the bonding element composed of several spherical elements and analyzed the influence of ballast particle shape and contact friction coefficient between ballast particles on the shear strength of ballast material.

A lot of research has also been done on the discrete simulation analysis of ballast bed. Huang and Chrismer [11] studied the influence of high-speed train load mode on the accumulation of track settlement in the discrete element simulation of ballast settlement under "critical speed" of train. Vizcarra et al. [12] introduced the numerical simulation results of the coarse particle loading test of simulated railway ballast bed, evaluated the deformation of ballast under vertical load, and studied the influence of two different particle size distributions on the deformation of ballast. Jing et al. [13] established a ballast-sleeper model based on the discrete element method by using PFC2C, in which the irregular disk cluster model was used to simulate particle movement and interaction mechanism, and then analyzed the deterioration mechanism of ballast breakage under monotonic and cyclic loads. Laryea et al. [14] simulated the ballast particles with complex shape by the composite spherical element which is built by the construction method of the minimum radius discrete element numerical model of the real particle shape. And the settlement of ballast bed under load between the composite element particles and the spherical element particles is contrastively analyzed. Yang et al. [15] obtained the shape characteristics of ballast particles by laser scanning technology and established a numerical model of ballast box under cyclic loading. The influence of ballast gradation on settlement characteristics of ballast bed was studied, and the settlement mechanism of ballast bed was analyzed from the microscopic view. Gao et al. [16] established a cluster ballast model which can simulate the real ballast shape and a single spherical ballast model and established the three-dimensional ballast-sleeper space model based on the two ballast models, respectively. The differences of the mechanical characteristics of the two ballasts under cyclic loading are analyzed, including contact force, coordination number, ballast stress, and vibration acceleration. Chang [17] built the ballast particle model by Fish language in PFC3D and the ballast box model with one sleeper and analyzed the influence of horizontal excitation force and vertical downward pressure on the mechanical characteristics of ballast bed. Based on field tests and discrete element simulation analysis, Khatibi et al. [18] studied the sensitivity of ballast depth, width, height, friction between particles, and ballast compactness. Liu [19] established the discrete element model of ballast bed on bridge by using the discrete element software EDEM and the influence of sleeper vibration on the stability of ballast bed on bridge.

In summary, the current research on ballasted bed is mostly on test and simulation analysis under cyclic load, while there is little research on operational effect of the dynamic track stabilizer. So, the operation technology of the dynamic track stabilizer is handled by experience mostly and their lack of corresponding theoretical guidance on quality control of ballast for dynamic stabilization operation. According to the existing experience in practical engineering, we can know that too many times of dynamic stabilization operation may reduce the quality of ballast bed and too few times operation can hardly meet the quality requirements of ballast bed. Therefore, it is necessary to study the influence of operation parameters of dynamic track stabilizer on the quality of ballast bed theoretically. In this paper, based on the discrete element method, a reduced three-dimensional discrete element simulation model of ballasted bed is established, and a ballast box test bench with the same proportion as the simulation model was built to carry out simulation analysis and experimental research under dynamic stabilization operation. Rationality of the discrete element simulation model of ballasted bed for stabilization operation and validity of the analysis results will be verified by comparing the results of experiment and simulation analysis. Change rules and trends of settlement, lateral resistance, and compactness of ballast bed under loads with different excitation frequencies during dynamic stabilization operation are analyzed comprehensively on the basis of the discrete element simulation model.

\section{Simulation Analysis of Ballast Bed under Dynamic Stabilization Operation}

In the study of railway ballast, the stress-strain and deformation rules of ballast particles can be visually displayed by the discrete element method. The deformation and displacement of the whole ballast bed can be simulated in macroscopic aspect, and the movement rule and contact force of ballast particles can be simulated in mesoscopic aspect. Through the simulation analysis of the discrete element method, the change rules of force and deformation of the ballast bed discrete body under dynamic stabilization operation are analyzed and explained theoretically.

2.1. Establishment of Ballast Particle Model. The shape of ballast particles is irregular and the edges are obvious, which makes the contact between particles complex and forces concentrated. As a typical discrete body, ballast particles are characterized significantly by nonuniformity, discontinuity, and anisotropy. The geometrical shape of ballast particle has obvious influence on the mechanical properties of ballast bed and the interaction mechanism between ballast particles. At the same time, ballast particles is an important part of ballasted track and its material properties play a direct role in the carrying capacity, deformation deterioration, maintenance of the ballast bed, and stability of train running. In this paper, the commonly used granite ballast particles are selected as the research object. The shape of the particles is shown in Figure 1, and the physical parameters of the granite ballast particles [20] are shown in Table 1. 


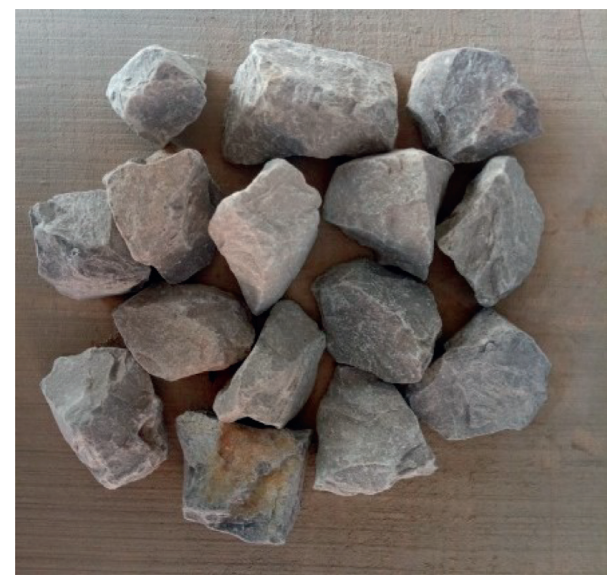

Figure 1: Granite ballast particles.

TABLE 1: Physical parameters of granite ballast particle.

\begin{tabular}{lccc}
\hline Physical parameters & Density $\left(\mathrm{kg} \cdot \mathrm{m}^{-3}\right)$ & Poisson ratio & Shear modulus $($ Pa) \\
\hline Granite ballast particle & 2400 & 0.3 & $3.58 \times 10^{9}$ \\
\hline
\end{tabular}

The size and shape of ballast particles are different. And the influence of ballast particles with different specifications on mechanical properties of ballast bed is different. The size of ballast particles used in normal ballasted railways ranges from 37 to $54 \mathrm{~mm}$ [21]. According to the research needs, the grain size distribution of ballast particle selected in this study is shown in Table 2.

In this paper, the balls are combined into complex ballast clusters which are like the actual ballast particles based on the discrete element software EDEM. The diameter of each ball is $10 \mathrm{~mm}$, and ballast particle clusters with different average diameters will be formed by different number of balls. The 8 typical ballast particle cluster models are established comparing with the shape and size of ballast particles in Figure 2, and characteristic description of each cluster is shown in Table 3. When building the ballast bed model, particle cluster models I, II, and III are used to simulate ballast particles with particle size less than $40 \mathrm{~mm}$. Particle cluster models IV, V, and VI are used to simulate ballast particles with particle size ranges from $40 \mathrm{~mm}$ to $50 \mathrm{~mm}$. And particle cluster models VII and VIII are used to simulate ballast particles with particle size greater than $50 \mathrm{~mm}$.

2.2. Establishment of Sleeper and Ballast Bed Model. To study the mechanical characteristics of ballast bed under dynamic stabilization operation, a three-dimensional ballast box simulation model with reduced size was established based on the ballast particle cluster model and literature [22]. When the size of ballast box is 8 times larger than the average particle size of ballast, the boundary effect of ballast box can be ignored [23]. And the average particle size of the ballast cluster model established in this paper is not more than $45 \mathrm{~mm}$, so the minimum size of ballast box can be set as $360 \mathrm{~mm}$. Combining with the specific experimental
TABLE 2: Grain size distribution of ballast particles.

\begin{tabular}{lcccc}
\hline Particle size $(\mathrm{mm})$ & $<31.5$ & $31.5 \sim 40$ & $40 \sim 50$ & $50 \sim 63$ \\
\hline Mass content $(\%)$ & 20 & 10 & 50 & 20 \\
\hline
\end{tabular}

requirements, the size of the three-dimensional model of the ballast box is set as $1000 \mathrm{~mm} \times 700 \mathrm{~mm} \times 550 \mathrm{~mm}$ (length $\times$ width $\times$ height). Considering the time and memory requirements of the simulation analysis scale, the established discrete element model only contains one sleeper, which is shown in Figure 3. The reduced sleeper model is established based on physical parameters of the Type III concrete sleeper, whose dimensional parameter is $500 \mathrm{~mm} \times 230 \mathrm{~mm} \times 160 \mathrm{~mm}$ (length $\times$ width $\times$ height). The content of ballast clusters is determined by the parameters in Table 2. And there are 19965 ballast clusters in the discrete element model.

2.3. Determination of Contact Parameters and Boundary Conditions in Simulation. During discrete element simulation analysis, the contact collision will occur between particles or between particles and sleepers, so it is particularly important to determine the relevant contact parameters. In this study, the Hertz-Mindlin nonsliding contact model was used to calculate contact force without considering the ballast breakage. The normal and tangential force component of the contact model is calculated based on Hertzian contact theory and Mindlin-Deresiewicz theory, respectively. According to the method in reference [24], the most consistent contact parameters are obtained by the inversion method in which the contact parameters of discrete element are set up many times and the numerical simulation results are compared with the experimental results every time. The restitution coefficient, static friction coefficient, and rolling 

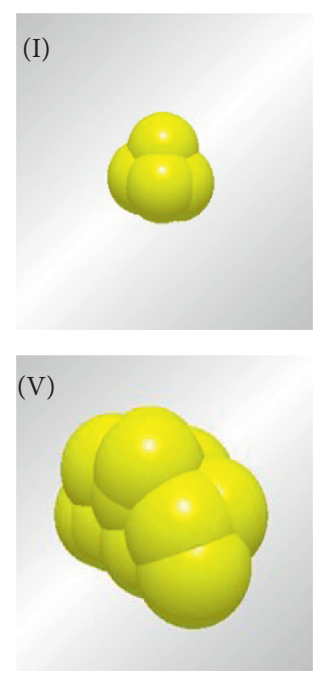
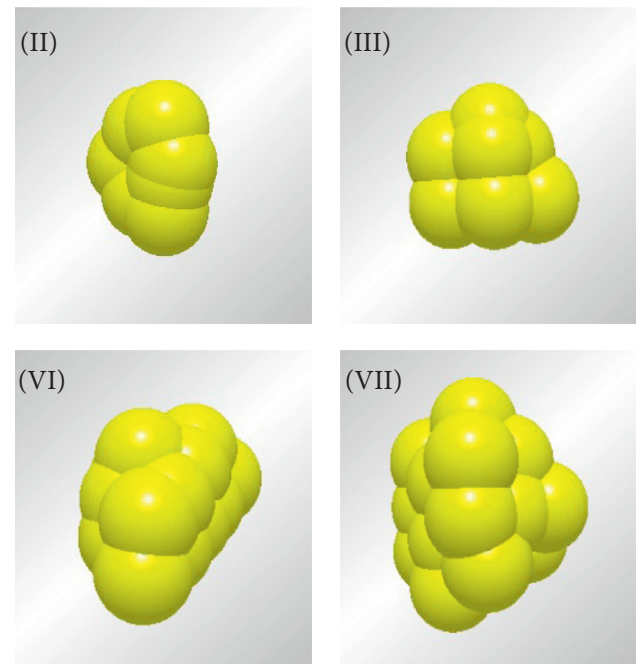
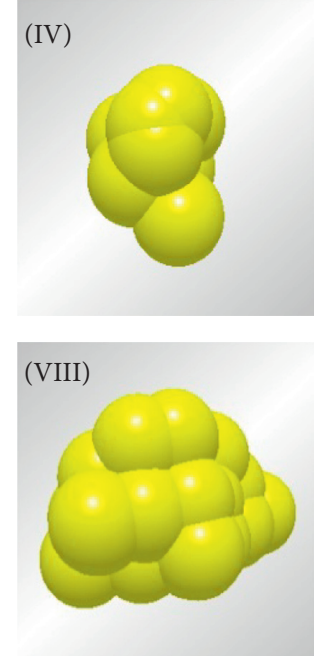

FIGURE 2: The typical ballast particle cluster model.

TABle 3: Characteristic description of ballast particles with different sizes.

\begin{tabular}{lccccccc}
\hline Particle cluster model & I & II & III & IV & V & VI & VI \\
\hline Number of balls & 5 & 7 & 8 & 10 & 14 & 16 & 20 \\
Average particle size $(\mathrm{mm})$ & 26 & 36 & 38 & 40 & 44 & 48 & 50 \\
\hline
\end{tabular}

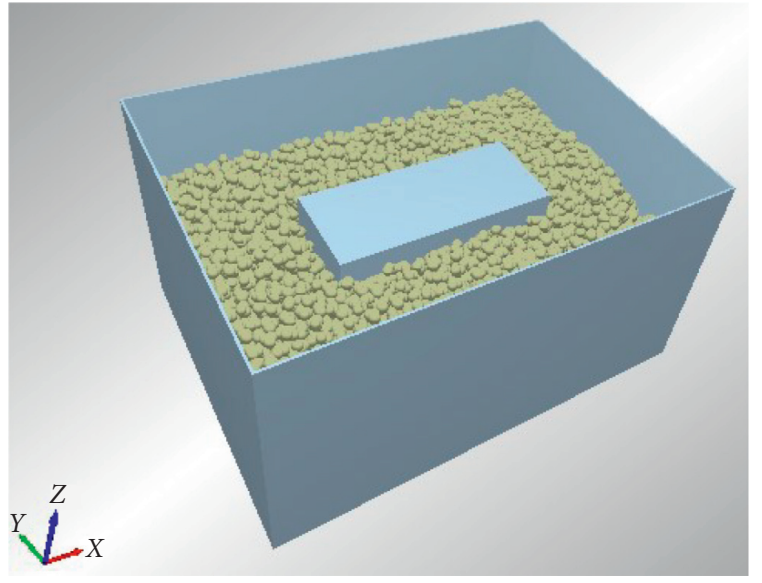

Figure 3: Three-dimensional model of sleeper and ballast bed.

friction coefficient between ballast particles and sleepers are shown in Table 4.

When the dynamic track stabilizer works, the transverse excitation force generated by the vibration of the stabilizer acts on rail through the clamp wheel and the running wheel of the stabilizer and then transfers to the sleeper. At the same time, the downward pressure of the downward pressure cylinder is transferred to the rail through the running wheel, which promotes the rail sinking. Under the combined action of vertical and transverse excitations, ballast particles move, fill, and compact with each other. This will enlarge the friction and embedded force between particles and increase the lateral resistance and overall stability, which ensures the safety performance of high-speed train running. Transverse excitation force belongs to sinusoidal excitation force, and the dynamic equation is $F_{e}(t)=M_{e} \omega^{2} \cos (\omega t)$, where $F_{e}(t)$ is the exciting force, $M_{e}$ is the static eccentricity, and $\omega$ is the angular frequency of the exciting shaft which can be applied to sleepers by the form of frequency and displacement amplitude. In the discrete element software EDEM, the load cannot be directly applied on sleeper, so the vertical downward pressure will be applied to the sleeper in the form of displacement; that is, the downward displacement value is directly applied to the sleeper in simulation process, and the displacement value was obtained by experiment.

2.4. Simulation Results of Ballast Bed under Dynamic Stabilization Operation. When the excitation frequency is $30 \mathrm{~Hz}$ and the excitation amplitude is $2 \mathrm{~mm}$, the settlement of sleeper can be measured by experiment as shown in Figure 4. The settlement of the sleeper is applied to the sleeper to simulate the effect of downward pressure, and the dynamic stabilization operation of the ballast system is simulated and analyzed. The microcharacteristic parameters such as displacement, angular displacement, and contact force of ballast particles and the macro-characteristic parameters such as displacement, compactness, and transverse resistance of the whole ballast are obtained under dynamic stabilization operation. Based on this, the influence of excitation frequency and other parameters on the relevant characteristic parameters can be further analyzed.

The angular velocity and extrusion force vector diagram of the ballast particles surrounding the sleeper at different times are shown in Figure 5. Each vector in a vector diagram is represented by a cylinder with an arrow at the contact 
TABle 4: Contact parameters.

\begin{tabular}{lcc}
\hline Contact parameters & Between ballast particles & Between ballast particle and sleeper \\
\hline Restitution coefficient $e$ & 0.5 & 0.5 \\
Static friction coefficient $\mu_{s}$ & 0.7 & 0.4 \\
Rolling friction coefficient $\mu_{r}$ & 0.2 & 0.1 \\
\hline
\end{tabular}

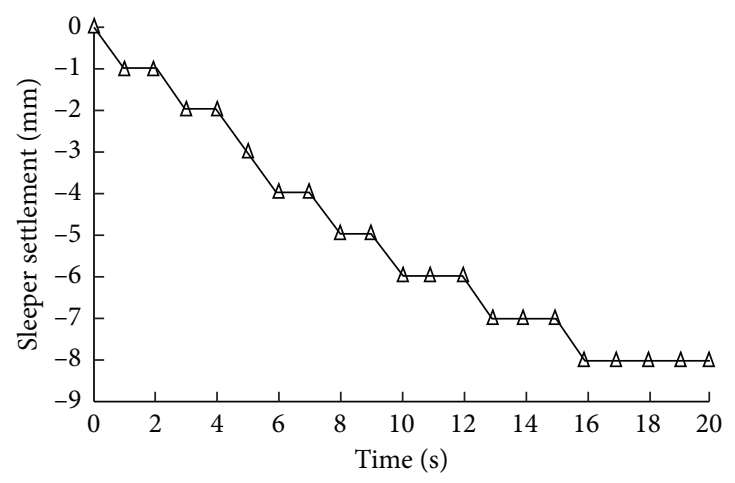

Figure 4: Settlement of the sleeper.

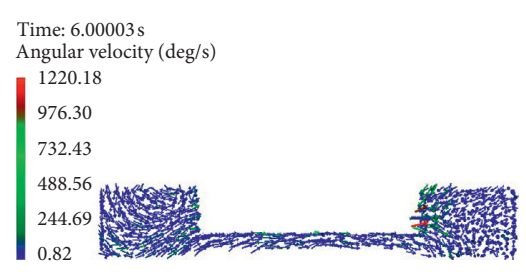

(a)

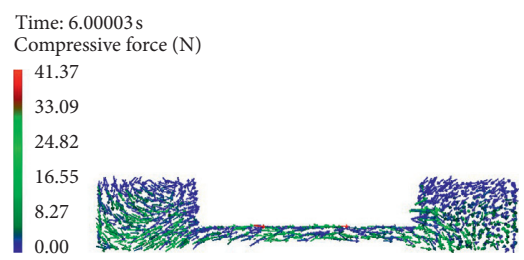

(d)

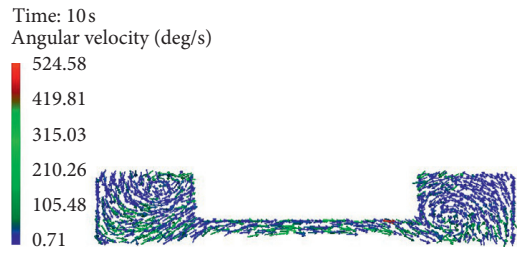

(b)

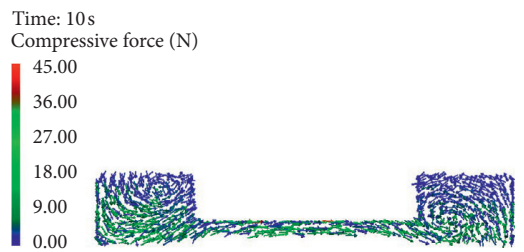

(e)

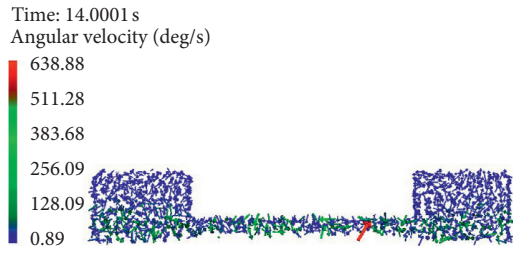

(c)

Time: $14.0001 \mathrm{~s}$

Compressive force $(\mathrm{N})$

52.50

42.06

31.61

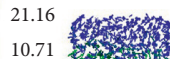

0.27

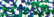


loads are applied on sleepers. At the same time, the measured settlement of the sleeper from experiment will be taken as the input condition of the discrete element simulation, which ensures the consistency of the boundary conditions between experiment and simulation.

3.1. Construction of Ballast Box Test Bench. The size of ballast box and sleeper is the same as that of the simulation analysis model. The ballast box is welded by using the steel plate, and the sleeper is poured according to the requirement of Type III concrete sleeper. The ballast box test bench is built as shown in Figure 6. And the vibration motor is installed on the sleeper. The ballast particle material is granite. According to the ballast gradation in Table 2, the ballast is naturally filled into the ballast box after mixing. When the filling height reaches $300 \mathrm{~mm}$, the sleeper and the vibration motor are placed in the middle of the ballast box, and the ballast with the height of $120 \mathrm{~mm}$ is filled into the ballast box again. The compactness of the ballast box during filling is 1700 to $2000 \mathrm{~kg} / \mathrm{m}^{3}$. The motor used is eccentric, which is used to simulate the transverse excitation force in dynamic stabilization operation. The nominal frequency of the motor is $50 \mathrm{~Hz}$, and the amplitude of the excitation displacement is $2 \mathrm{~mm}$. The change of the excitation frequency is realized by using the frequency modulator. Vertical downward pressure is simulated by the mass of the sleeper and vibration motor. The total mass is $55 \mathrm{~kg}$.

3.2. Establishment of Test System and Selection of Test Methods. The compactness, settlement, transverse resistance, and vibration acceleration response of ballast bed under dynamic stabilization operation will be analyzed in this paper. The compactness of ballast bed is usually measured by the irrigation method. The settlement of ballast bed is measured by using a laser range finder. The instruments used to measure transverse resistance are pressure sensor, jack, and dial indicator.

The ballast acceleration can fully reflect the vibration characteristics of the ballast bed during dynamic stabilization operation. The triaxial accelerometer is installed at $100 \mathrm{~mm}$ below the bottom of the sleeper to measure the lateral, longitudinal, and vertical vibration acceleration. Acceleration response signal is collected and processed by dynamic signal testing and analysis system. The laser range finder is installed in the proper position above the sleeper to accurately measure the vertical displacement of the ballast bed and sleeper during dynamic stabilization operation. The sleeper adopts III concrete sleepers, and the physical parameters of III concrete sleepers [8] are shown in Table 5. The positions of the accelerometer and laser range finder are shown in Figure 7.

The installation positions of pressure sensor, Jack, and dial indicator for measuring transverse resistance are shown in Figure 8. The pressure sensor relates to a digital display meter, which can read the pressure value from digital display by jack loading, while the micrometer shows the magnitude of transverse displacement. The pressure sensor external digital display meter, through the jack loading, can read the

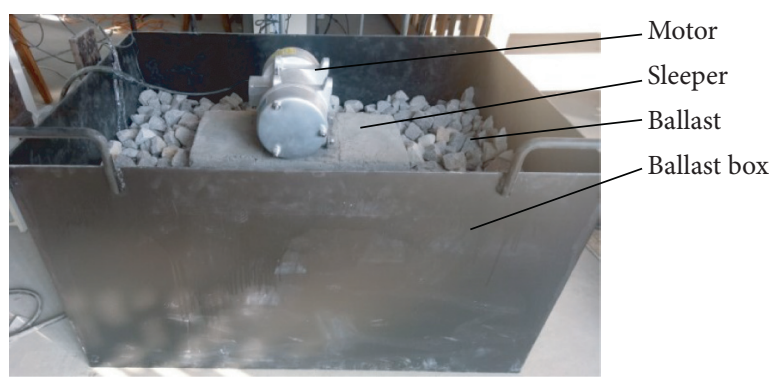

Figure 6: Ballast box for experiment.

TABle 5: Material properties of Type III concrete sleepers.

\begin{tabular}{lccc}
\hline $\begin{array}{l}\text { Physical } \\
\text { parameters }\end{array}$ & $\begin{array}{c}\text { Density } \\
\left(\mathrm{kg} \cdot \mathrm{m}^{-3}\right)\end{array}$ & $\begin{array}{c}\text { Poisson } \\
\text { ratio }\end{array}$ & $\begin{array}{c}\text { Shear modulus } \\
(\mathrm{Pa})\end{array}$ \\
\hline Property value & 3000 & 0.25 & $3 \times 10^{7}$ \\
\hline
\end{tabular}

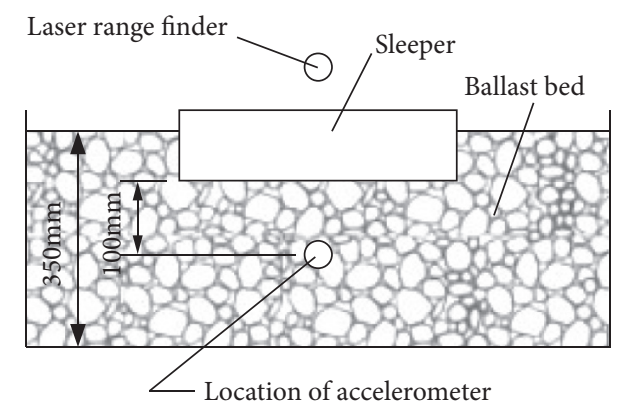

FIGURE 7: Schematic diagram of sensor position.

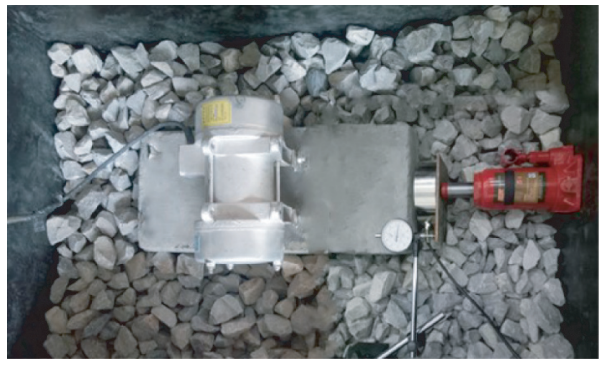

FIgURE 8: Schematic diagram of pressure sensor position.

pressure value from digital display, while the dial indicator displays the size of transverse displacement value.

\subsection{Experiment Results of Ballast Box under Dynamic Sta-} bilization Operation. Horizontal excitation frequencies of dynamic track stabilizer range from 0 to $45 \mathrm{~Hz}$. Gao et al. [16] obtained the optimal excitation frequency of dynamic stabilization operation using discrete element simulation in PFC3D, which was $30 \mathrm{~Hz}$. Yan [25] combined experiment and simulation, and the optimal excitation frequency of dynamic stabilization operation is determined to be $28 \mathrm{~Hz}$. Due to the limitation of the excitation motor in the reduced proportion ballast box test bench established in this paper, the initial experiment result shows that when the excitation frequency is small, the vibration of the sleeper is weak, and 
the corresponding stabilization effect is not obvious. So, the final 6 excitation frequencies are $30 \mathrm{~Hz}, 32 \mathrm{~Hz}, 34 \mathrm{~Hz}, 36 \mathrm{~Hz}$, $38 \mathrm{~Hz}$, and $40 \mathrm{~Hz}$. The rated frequency of the eccentric vibration motor is $50 \mathrm{~Hz}$, which cannot be changed directly. The excitation frequency can be adjusted by using a frequency converter to meet the requirements of different frequencies. When the excitation frequency is $36 \mathrm{~Hz}$, the acceleration time history curves of lateral and vertical vibration of ballast bed are shown in Figure 9. The sampling frequency is $2 \mathrm{kHz}$. And the selected acceleration time history curve contains 48,000 data points. The mean square value of each data point is calculated for 1000 data points at intervals. The mean square values of lateral and vertical acceleration of the ballast bed corresponding to different excitation frequencies are obtained and shown in Figure 10.

From Figure 10, the mean square acceleration of ballast bed is different under different frequencies at beginning. This is because the initial compactness of the ballast bed is different and the energy corresponding to each frequency is different. The mean square value of transverse vibration acceleration is larger than that of vertical vibration, which shows that the energy transferred to the ballast bed along the transverse vibration direction is larger than that along the vertical vibration direction when dynamic track stabilizer is working. Therefore, transverse vibration plays a dominant role in dynamic stabilization operation. With the dynamic stabilization operation proceeding, the mean square value of the vibration acceleration of the ballast bed gradually increases and finally tends to be stable. This is because the mean square value of acceleration is proportional to the vibration energy. The process of ballast from loose to dense belongs to the process of entropy reduction, which absorbs a lot of energy. With the ballast becoming compact, the energy loss from the vibration source to ballast gradually decreases and the energy at the measuring position gradually increases; that is, the mean square value of acceleration gradually increases and finally tends to be stable. The mean square value of vibration acceleration of ballast bed is the largest when the frequency of excitation is $36 \mathrm{~Hz}$ at the same time of stabilization operation, and the effect of stabilization operation on ballast bed is the better.

\section{Mechanical Characteristics Analysis of Ballast Bed in Dynamic Stabilization Operation}

The main mechanical parameters of ballast bed include ballast bed elasticity, sleeper lateral resistance, ballast particle angular acceleration, ballast vibration velocity and acceleration, and ballast bed settlement and compactness. Combining with the content of this study, the parameters of ballast compactness, settlement, and lateral resistance of sleepers will be focused, and the effects of different excitation frequencies on these mechanical properties of ballast bed will be studied.

\subsection{Effect of Excitation Frequency on Compactness of Ballast} Bed. The compactness of ballast bed reflects the tightness degree of ballast particles. The calculation method of ballast compactness in simulation analysis is to calculate the ratio of ballast volume to the whole volume in a selected space. In this simulation test, a space with $200 \mathrm{~mm} \times 100 \mathrm{~mm} \times 100 \mathrm{~mm}$ directly below the sleeper is selected as the compactness measurement space. The variations of compactness of ballast bed under the action of dynamic stabilization operation at different frequencies are shown in Figure 11.

As can be seen from Figure 11, the initial compactness of ballast bed is the same because the initial state of ballast bed before dynamic stabilization operation in simulation can be controlled. With the progress of dynamic stabilization operation, the compactness of ballast bed increases gradually and finally tends to be stable. This is because the ballast bed is relatively loose in the initial stage, and its compactness is relatively small. During the stabilization operation, the ballast particles are recombined, the ballast gradually becomes compact, and the compactness of the ballast bed reaches a certain degree and tends to be stable. Because the compactness of ballast cannot be measured in dynamic stabilization operation experiment, it can only measure the compactness of ballast before and after stabilization. The variations of compactness of ballast bed before and after stabilization under dynamic stabilization operation with different frequencies are shown in column Figure 12(a), and the corresponding simulation results are shown in Figure 12(b).

It can be seen from Figure 11 that the compactness of ballast bed increases obviously after dynamic stabilization operation, and with the increase in transverse excitation frequency, the compactness of ballast bed after dynamic stabilization operation increases first and then decreases. When the excitation frequency is $36 \mathrm{~Hz}$, the compactness of ballast bed is the largest, and the corresponding increment of compactness is also the largest. This shows that when the excitation frequency is $36 \mathrm{~Hz}$, the corresponding ballast box compaction effect is better. At the same time, the trend of the experimental results is consistent with the simulation results, and the error of the results is less than $4 \%$. It shows that the results obtained from the simulation analysis using the discrete element method are effective.

\subsection{Effect of Excitation Frequency on Settlement of Ballast Bed.} Proper ballast settlement will make the train run safer and the ballast life longer. The unreasonable settlement of ballast bed will cause uneven settlement of sleepers, decrease the smoothness of train running, affect the comfort of train, and even cause train rollover. When ballast bed is operated under dynamic stabilization operation, the vibration of sleeper and ballast causes the ballast particle to move each other, and the settlement deformation of ballast is caused by the compaction of ballast bed. And the disordered arrangement of ballast particles and the magnitude of vibration have a great influence on the settlement of the whole ballast bed.

The settlement of ballast bed obtained in dynamic stabilization operation experiment varies with the excitation frequency and is shown in Figure 13. It can be seen from Figure 13 that when the excitation frequency is constant, the 


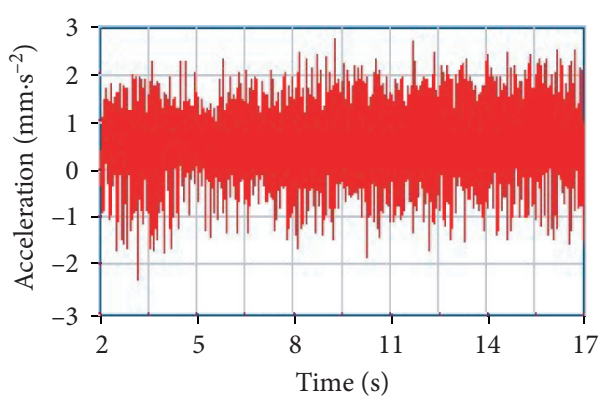

(a)

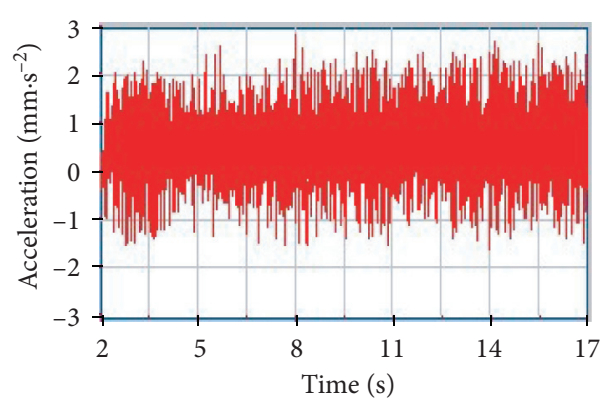

(b)

FiguRE 9: Vibration acceleration time history curve of ballast bed when excitation frequency is $36 \mathrm{~Hz}$ : (a) transverse direction; (b) vertical direction.

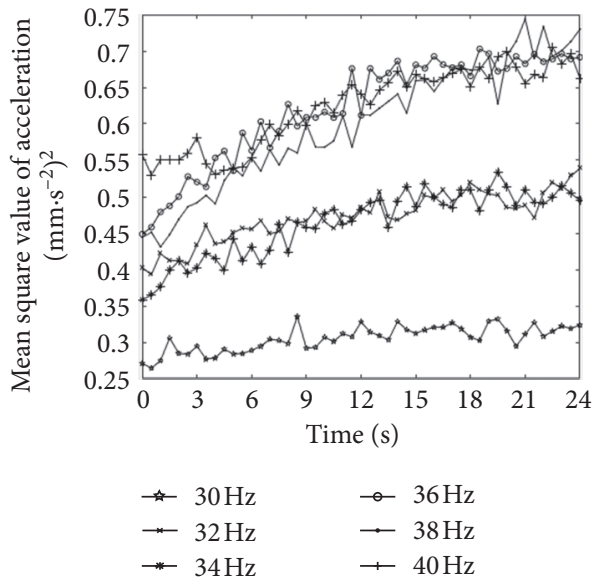

(a)

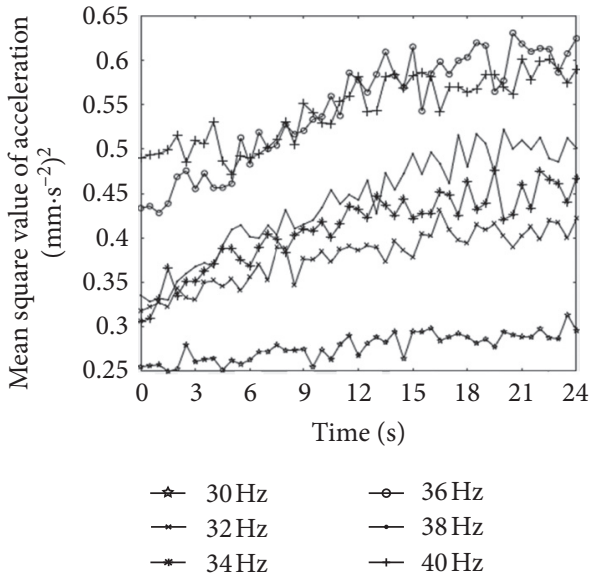

(b)

FIGURE 10: Mean square value of vibration acceleration of ballast bed at different frequencies: (a) transverse direction; (b) vertical direction.

settlement trend of ballast bed is basically the same as that under cyclic loading. The settlement includes two stages: the rapid settlement stage in the initial stage of dynamic stabilization operation and the slow settlement stage after stabilization. Because of the elasticity of the ballast particles, the settlement curves will fluctuate to a certain extent. The experiment results of the ballast settlement trend in this paper are basically the same as those in reference [18] under dynamic stabilization operation. This is because the ballast bed in the early stage is relatively loose and has low compactness. The ballast particles are rapidly compacted under dynamic stabilization operation, and the settlement increases rapidly. With the stabilization operation going on, the ballast bed compacted gradually, and the stability improved gradually, so the settlement of the ballast bed is gradually slowed down. With the increase in excitation frequency, the settlement of ballast bed increases first and then decreases. When the excitation frequency is $36 \mathrm{~Hz}$, the settlement of the stabilized ballast bed is the largest.

4.3. Effect of Excitation Frequency on Transverse Resistance of Ballast Bed. Transverse resistance of ballast bed is an important factor to ensure the stability of railway line and the safety of train running. It is also an important reference standard for the design of new railway and inspection of existing railway. The contact, accumulation, and interaction between ballast particles and sleepers play a direct role in the transverse resistance of ballast bed.

In the ballast transverse resistance experiment, the transverse thrust is generated by using the jack, the transverse resistance value is displayed by using the digital display meter of the pressure sensor, and the display values of the indicator are the transverse displacement of the sleeper (as shown in Figure 8). Transverse resistance data of the sleeper are recorded once every $0.5 \mathrm{~mm}$ transverse displacement interval until the transverse resistance value keeps basically unchanged with increase in sleeper displacement. The transverse resistance value at this time is regarded as its limit value. The average value is obtained after multiple measurements. Finally, when the transverse displacement of sleeper is $3 \mathrm{~mm}$, the force of the pressure sensor is the transverse resistance of the ballast bed in ballast box. The transverse resistance curves of ballast bed in ballast box measured after dynamic stabilization operation with different excitation frequencies are shown in Figure 14(a). The horizontal ordinate in the figure represents the transverse displacement of sleepers and the longitudinal coordinate 


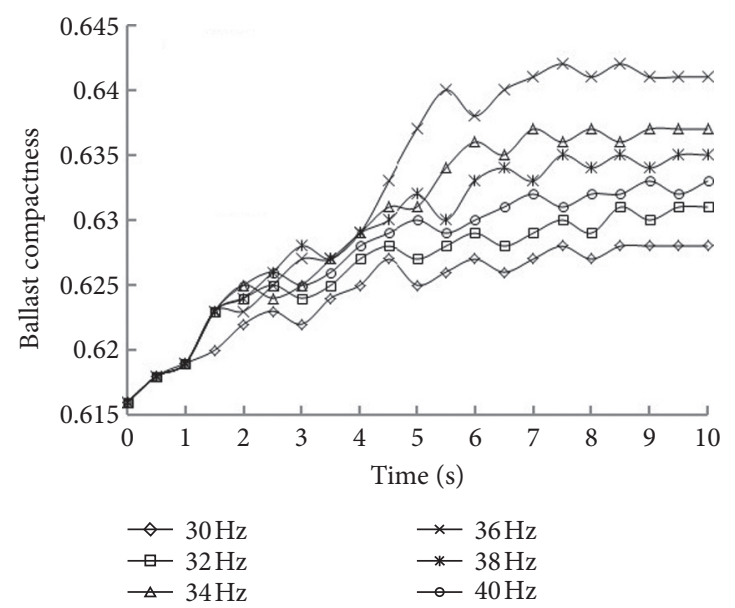

FIGURE 11: Simulation analysis results of ballast compactness after different frequency excitations.

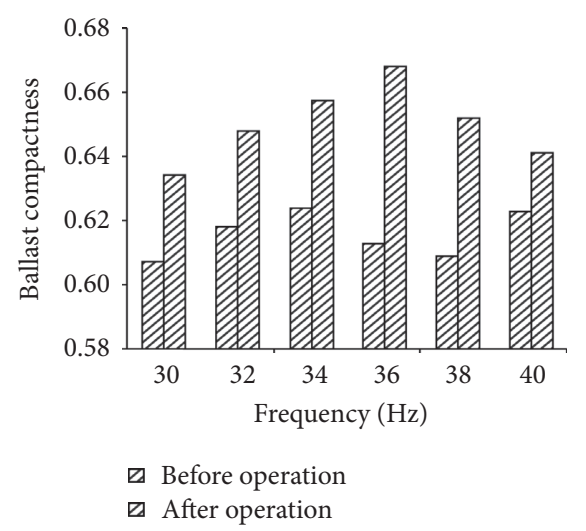

(a)

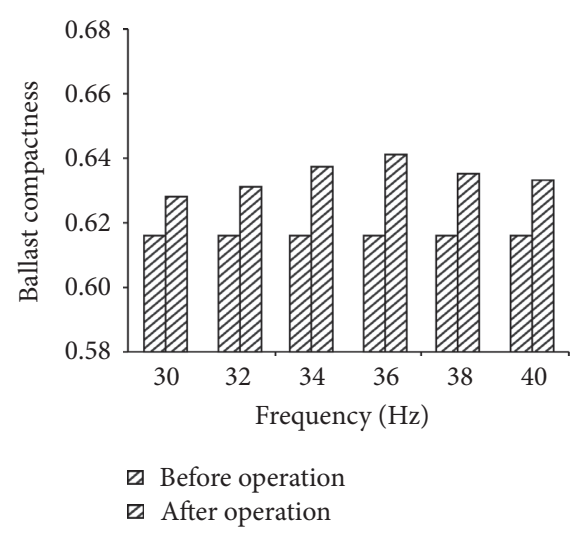

(b)

FIGURE 12: Track bed compactness variation diagram: (a) experimental result; (b) simulation result.

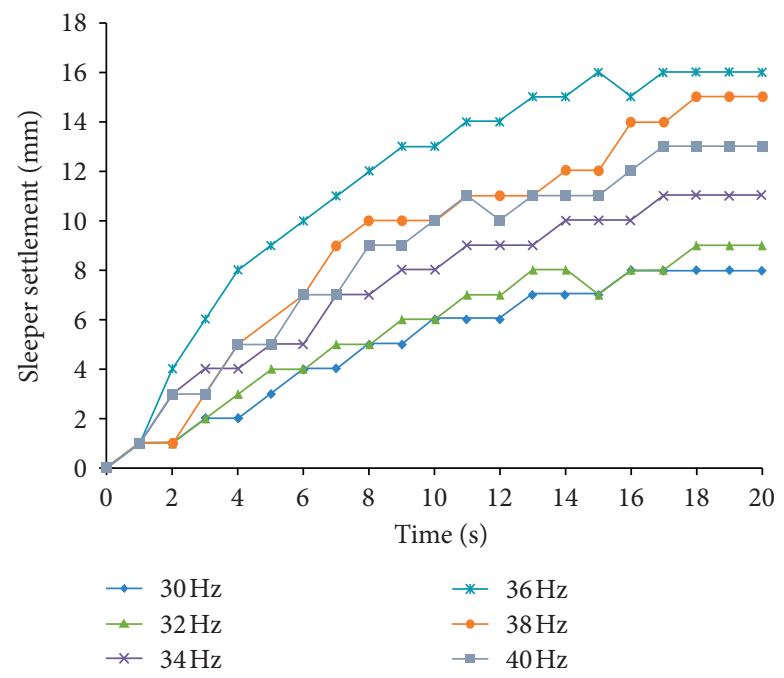

Figure 13: Ballast bed settlement trend chart. 


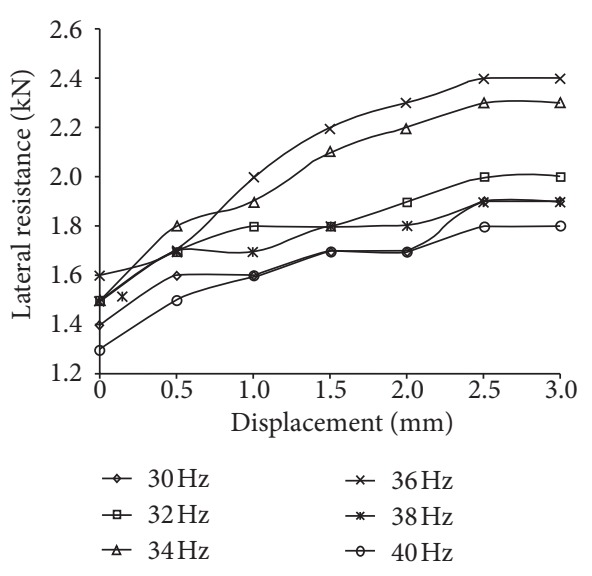

(a)

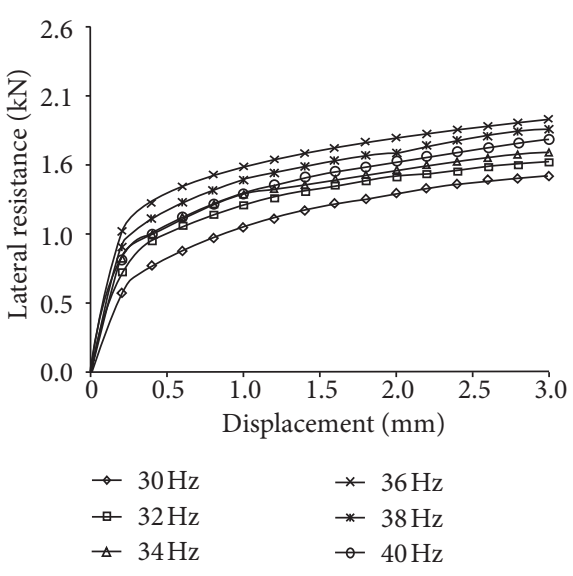

(b)

Figure 14: Transverse resistance of ballast bed after stabilization operation with different excitation frequencies: (a) experimental result; (b) simulation result.

represents the transverse resistance of ballast bed. Similarly, based on the discrete element simulation analysis, the transverse displacement of sleepers for $3 \mathrm{~mm}$ acts on stabilized ballast bed, and the force values of the sleeper during movement are the transverse resistance of ballast bed. From this, the curves of the transverse resistance of ballast bed with different frequencies varying with the transverse displacement of sleeper are obtained, which are shown in Figure 14(b). The error rates of the test results and numerical simulation results of the transverse resistance of the ballast bed after dynamic stabilization operation are shown in Table 5.

From Figure 13, the transverse resistance of the stabilized ballasted bed increases with the increase in transverse displacement of sleeper. As shown in Figure 13(a), the initial experimental value of transverse resistance is not zero. This is because the pressure gauge must have a certain initial extrusion during experiment. When horizontal excitation frequency is constant, the transverse resistance of the ballast bed increases first and then tends to be stable with the increase in the lateral displacement of the sleeper. Because the sleeper in the process of transverse driving, transverse resistance of sleepers is increasing. When the transverse resistance reaches its limit, it remains stable. The resistance value currently is the value of the transverse resistance of the stabilized ballast bed. With the increase in excitation frequency, the transverse resistance of ballast bed increases first and then decreases. When the excitation frequency is $36 \mathrm{~Hz}$, the transverse resistance of ballast bed reaches its maximum. The stabilization effect of ballast bed is the best.

As can be seen from Table 6, when the excitation frequency is small, the error ratio between the simulation results and the experimental results of the transverse resistance of the stabilized ballast bed is larger. This is because the ballast particle cluster model used in simulation analysis is composed of small particles. The surface of the particle cluster is rounder, and when the sleeper moves transversely, the particles move easily, so the transverse resistance value is
TABLE 6: Error rate of transverse resistance under different frequencies.

\begin{tabular}{lllllll}
\hline Excitation frequency $(\mathrm{Hz})$ & 30 & 32 & 34 & 36 & 38 & 40 \\
\hline Error rate $(\%)$ & 21 & 20 & 26 & 21 & 5 & 0 \\
\hline
\end{tabular}

smaller. However, in experiment, ballast particles have many edges and angles. When sleepers move transversely, the friction between ballast particles is very large and not easy to move between each other. Therefore, the experimental result value of transverse resistance is larger, which makes the error rate of ballast bed transverse resistance larger.

\section{Conclusion}

In this paper, a discrete element model of ballast bed is established based on the discrete element method, and a ballast box test bench is built to analyze the mechanical characteristics of ballast bed under dynamic stabilization operation. The transverse resistance and compactness of the experimental results and the numerical simulation results are compared. The rationality of the discrete element model and the validity of the simulation results are verified. At the same time, the settlement, transverse resistance, and compactness of ballast bed under different frequencies of the three-dimensional discrete element model and ballast box test bench are obtained. At the same time, the three-dimensional discrete element model of ballasted bed and the numerical values of settlement, transverse resistance, and compactness of ballasted bed under different frequencies in ballast box test are obtained. By in depth analyses of the above simulation and experimental results, the following conclusions are drawn.

When the excitation frequency is not changed, with the dynamical stabilization operation, the transverse resistance of the ballast bed, the settlement of the sleeper, and the compactness of the ballast bed in the area directly below the sleeper increase first and then tend to be stable. 
Under different horizontal excitation frequencies, when the excitation frequencies increase from $30 \mathrm{~Hz}$ to $36 \mathrm{~Hz}$, the transverse resistance of the ballast bed, the settlement of the sleeper, and the compactness of the ballast bed in the area directly below the sleeper increase gradually, and when the excitation frequencies increase from $36 \mathrm{~Hz}$ to $40 \mathrm{~Hz}$, the above three mechanical properties decrease gradually. It is concluded that the relative optimal excitation frequency of the ballast box test bench during stabilization is $36 \mathrm{~Hz}$.

\section{Data Availability}

The data used to support the findings of this study are included within the article.

\section{Conflicts of Interest}

The authors declare that they have no conflicts of interest.

\section{Acknowledgments}

This work was supported by the National Natural Science Foundation of China (no. 51765023).

\section{References}

[1] F. Zhao, Dynamic Track Stabilizer, China Railway press, Beijing, China, 2006.

[2] M. Y. Fattah, M. R. Mahmood, and M. F. Aswad, "Settlement of railway track on reinforced ballast overlain by clayey," Journal of Transportation and Logistics, vol. 5, no. 2, p. 14, 2020.

[3] M. Y. Fattah, M. R. Mahmood, and M. F. Aswad, "Stress distribution from railway track over geogrid reinforced ballast underlain by clay," Earthquake Engineering and Engineering Vibration, vol. 18, no. 1, pp. 77-93, 2019.

[4] M. Y. Fattah, M. R. Mahmood, and M. F. Aswad, "Effect of track speed on the behavior of railway track ballast system underlain by clay," in Proceedings of the IOP Conference Series: Materials Science and Engineering, Chennai, India, September 2020.

[5] M. Y. Fattah, M. R. Mahmood, and M. F. Aswad, "Experimental and numerical behavior of railway track over geogrid reinforced ballast underlain by soft clay," Egypt: Recent Developments in Railway Track and Transportation Engineering, vol. 14, 2017.

[6] L. Gao, L. Qi, Xu Yang, H. Jiang, and C. Qu, "Effects of ballast bed section dimension on its lateral resistance," Journal of Southwest Jiao Tong University, vol. 49, no. 6, pp. 954-960, 2014.

[7] H. Liu, J. Xiao, M. Chen, C. Rong, and P. Wang, "Experimental study on resistance of granular ballast bed under cyclic longitudinal loading," Journal of the China Railway Society, vol. 163, no. 6, pp. 107-114, 2017.

[8] X. Wang, Study on the Cyclic Loading Test Equipment of Ballast Bed and Research on Relative Characteristics of Ballast bed, Kunming University of science and technology, Kunming, China, 2017.

[9] Y. Guo, Y. Ji, Q. Zhou, V. Markine, and G. Jing, "Discrete element modelling of rubber-protected ballast performance subjected to direct shear test and cyclic loading," Sustainability, vol. 12, no. 7, p. 2836, 2020.
[10] J. Zhao, Y. Yan, and S. Ji, "Analysis of direct shear test of soilrock mixture based on discrete element model," Chinese Journal of Solid Mechanics, vol. 35, no. 2, pp. 124-134, 2014.

[11] H. Huang and S. Chrismer, "Discrete element modeling of ballast settlement under trains moving at "Critical Speeds"," Construction and Building Materials, vol. 38, no. Supplement C, pp. 994-1000, 2013.

[12] G. C. Vizcarra, S. Nimbalkar, and M. Casagrande, "Modeling behaviour of railway ballast in prismoidal apparatus using discrete element method," Procedia Engineering, vol. 143, pp. 1177-1184, 2016.

[13] G. Jing, F. Kun, L. Gao, and J. Wang, "DEM simulation of ballast degradation and breakage under cyclic loading," Journal of Southwest Jiao Tong University, vol. 47, no. 2, pp. 187-191, 2012.

[14] S. Laryea, M. Safari Baghsorkhi, J.-F. Ferellec, G. R. McDowell, and C. Chen, "Comparison of performance of concrete and steel sleepers using experimental and discrete element methods," Transportation Geotechnics, vol. 1, no. 4, pp. 225-240, 2014.

[15] X. Yang, L. Gao, X. Cai, B. Hou, and Y. Zhao, "Influences of ballast gradation on railway ballast bed dynamic characteristics based on laser scanning and discrete element method," Journal of Vibration and Shock, vol. 36, no. 5, pp. 127-133, 2017.

[16] L. Gao, L. Qi, Xu Yang, and C. Ma, "Railway ballast bed mechanical property based on discrete element method," Journal of Tongji University (Natural Science), vol. 42, no. 7, pp. 1064-1069, 2014.

[17] L. Chang, Study on Operation Mechanism and Technology of Large-Scale Maintenance Machine Used in High-Speed Railway Ballast Bed, Beijing Jiao Tong University, Beijing, China, 2016.

[18] F. Khatibi, M. Esmaeili, and S. Mohammadzadeh, "DEM analysis of railway track lateral resistance," Soils and Foundations, vol. 57, no. 4, pp. 587-602, 2017.

[19] G. Liu, Study on Stability of Ballast Beds on Bridges based on Discrete Element Method, Southwest Jiao Tong University, Chendou, China, 2018.

[20] S. Zeng, Railway Granular Track Bed, China Railway Publishing House, Beijing, China, 1997.

[21] R. J. Bathurst and L. Rothenburg, "Micromechanical aspects of isotropic granular assemblies with linear contact interactions," Journal of Applied Mechanics, vol. 55, no. 1, p. 17, 1988.

[22] B. Indraratna, N. T. Ngo, C. Rujikiatkamjorn, and J. S. Vinod, "Behavior of fresh and fouled railway ballast subjected to direct shear testing: discrete element simulation," International Journal of Geomechanics, vol. 14, no. 1, pp. 34-44, 2014.

[23] P. Xiong Yazhi and R. Zhou, "Using the new track failure theory to try to calculate the track subsidence (Part 2)," Railway Construction, no. 7, pp. 35-36, 1981.

[24] T. Zhou, Study on Mechanical Properties and Parameter Optimization of Tamping on High Speed Ballast Railway, Kunming University of science and technology, Kunming, China, 2017.

[25] B. Yan, Research on Dynamic Mechanical Characteristics in the Operating Process of Dynamic Track Stabilizer, Kunming University of science and technology, Kunming, China, 2017. 